\title{
Laplace Transform, Application In Population Growth
}

\author{
Alfred Daci, Saimir Tola
}

\begin{abstract}
Laplace transformation is an important chapter of Mathematical Analysis. It has wide applications in different fields of engineering and techniques besides basis sciences and mathematics. In this paper we will become acquainted with the basic concepts of operational mathematics, some properties of Laplace Transform and its application in demography. The purpose of this paper is to utilize the Laplace transformation to extract the logistic equation and to use the logistic equation in population projections.
\end{abstract}

Keywords: Laplace transform, Inverse Laplace transform, population growth model, projection.

\section{Introduction}

The operational methods are original and quite widespread methods in solving different problems. They are applied in various fields of science. In this paper, we used Laplace transform for solving population growth. In everyday life, mathematical applications and models are commonly used. The ability to forecast the population and even answer some interesting questions about the population in the past relies on the development of precise population growth mathematical models. A population is "a group of the same species of crops, animals or other organisms which live together and reproduces." The logistic equation is an equation with separable variables, but we will use the transformation of Laplace and its own properties to find the exponential equation. [1]

\section{Definition of Laplace Transform}

Let it be $f(t)$ a complex function of the real $t$ argument given in the segment $[a, b]$. As it is known, such a function may appear in the form: $f(t)=u(t)+i v(t)$. We will be limited to the integral of the functions $f(t)$ that meets these conditions:

a) The function $f(t)$ is continuous in $(0,+\infty)$ combined with its derivatives up to any necessary order, with the exception of possibly a finite number of first type of critical points in each finite segment.

Revised Manuscript Received on July 05, 2019.

Alfred Daci ${ }^{1}$ and Saimir Tola ${ }^{1}$

${ }^{1}$ Faculty of Mathematical and Physical Engineering - Polytechnic University of Tirana

b) $f(t)=0$ for $t<0$.

c) The function $f(t)$ increases in absolute value no sooner than an exponential function. So there are numbers $M>0$ and $S_{0}>0$ such that for each term

$t$ we have: $|f(t)|<M e^{S_{0} t}$. [2], [5], [6]

Definition. The Laplace transform of the of the function $f(t)$ is called integral

$$
F(s)=\int_{0}^{+\infty} f(t) e^{-s t} d t
$$

where $s$ is a complex number $s=p+i \omega$ provided that $\operatorname{Re} s=p>S_{0}$.

The function $F(s)$, is called the Laplace function picture The function is referred to as the initial function. As mentioned earlier, the completion of the three requirements above is necessary to be the initial function $f(t)$. The following features only fulfill those three requirements are called original. From the practical perspective, this tightening of the original class is not very reasonable.

If $F(s)$, is a reflection of the function $f(t)$, then it says:

$$
L\{f(t)\}=F(s), \quad \text { or } F(s) \stackrel{\bullet}{\bullet} f(t) .
$$

Theorem. If the function $F(s)$, is an image, then: $F(s) \rightarrow 0$ when $\operatorname{Re} s=p \rightarrow+\infty$.

Based on this theorem it can be said that the necessary condition for a given function $F(s)$, to be an image of a function $f(t)$ is to complete the reconciliation:

$$
\lim _{\operatorname{Re} s \rightarrow+\infty} F(s)=0
$$

Examples of Laplace Transforms

1) The Laplace Transform of impulse function:

$$
\sigma(t)=\left\{\begin{array}{lll}
0 & \text { for } & t<0 \\
1 & \text { for } & t \geq 0
\end{array}\right.
$$

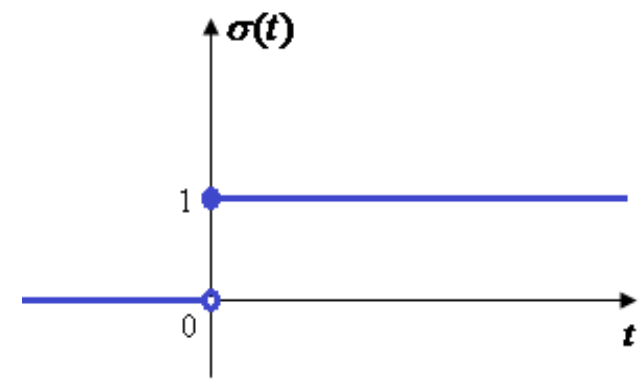

Fig. 1 
The function $\sigma(t)$ is original because it meets the three conditions for being such. Let's find the reflection of $\sigma(t)$;

$$
L\{\sigma(t)\}=\int_{0}^{+\infty} e^{-s t} \cdot 1 d t=-\left.\frac{e^{-s t}}{s}\right|_{0} ^{+\infty}=\frac{1}{s} .
$$

2) The Laplace Transform of function $f(t)=t$, is given by:

$F(s)=\int_{0}^{+\infty} e^{-s t} \cdot t d t=\left.\frac{t e^{-s t}}{-s}\right|_{0} ^{+\infty}+\frac{1}{s} \int_{0}^{+\infty} e^{-s t} d t=-\left.\frac{1}{s^{2}} e^{-s t}\right|_{0} ^{+\infty}=\frac{1}{s^{2}}$

3) The Laplace Transform of function $f(t)=e^{a t}$,

where $a \in C$ is given by:

$$
F(s)=\int_{0}^{+\infty} e^{-s t} \cdot e^{a t} d t=\int_{o}^{+\infty} e^{-(s-a) t} d t=\frac{1}{s-a}
$$

provided that $\operatorname{Re}(s-a)>0$, so $L\left\{e^{a t}\right\}=\frac{1}{s-a}$.

\section{Properties of Laplace Transform}

The use of operational methods simplifies the solution of many problems and, in particular, the solution of differential equations. To find out the inverse when the original is provided, or vice versa, ready - made tables that represent the connection between the original and reflection can be used. However, the problem cannot be solved only with a table because they cannot, however long, include all the cases of reflections that may appear. For this reason, different methods of finding the originals have been elaborated, but for the presentation of these methods, first of all, the properties of the reflection of Laplace should be known. We are now going to present some of the basic properties of the Laplace transformation.

\section{Linearity property of Laplace transform}

If $L\left\{f_{1}(t)\right\}=F_{1}(s)$ and $L\left\{f_{2}(t)\right\}=F_{2}(s)$ then

$$
L\left\{c_{1} f_{1}(t)+c_{2} f_{2}(t)\right\}=c_{1} F_{1}(s)+c_{2} F_{2}(s)
$$

This is clear since the integral of the sum is equal to the sum of the integrals. However, we will prove it;

$$
\begin{aligned}
& L\left\{c_{1} f_{1}(t)+c_{2} f_{2}(t)\right\}=\int_{0}^{+\infty} e^{-s t}\left[c_{1} f_{1}(t)+c_{2} f_{2}(t)\right] d t= \\
& =\int_{0}^{+\infty} e^{-s t} c_{1} f_{1}(t) d t+\int_{0}^{+\infty} e^{-s t} c_{2} f_{2}(t) d t
\end{aligned}
$$$$
=c_{1} \int_{0}^{+\infty} e^{-s t} f_{1}(t) d t+c_{2} \int_{0}^{+\infty} e^{-s t} f_{2}(t) d t=c_{1} F_{1}(s)+c_{2} F_{2}(s)
$$

\section{Shifting property of Laplace transform}

$$
\text { If } L\{f(t)\}=F(s) \Rightarrow L\left\{e^{\lambda t} f(t)\right\}=F(s-\lambda)
$$

Proof.

$$
L\left\{e^{\lambda t} f(t)\right\}=\int_{0}^{+\infty} e^{-s t} e^{\lambda t} f(t) d t=\int_{0}^{+\infty} e^{-(\mathrm{s}-\lambda) t} f(t) d t=F(s-\lambda)
$$

where $\operatorname{Re}(s-\lambda)>S_{0}$

\section{Original derivation property of Laplace transform}

If $L\{f(t)\}=F(s) \Rightarrow L\left\{f^{\prime}(t)\right\}=s F(s)-f(0)$

Proof.

$$
L\left\{f^{\prime}(t)\right\}=\int_{0}^{+\infty} e^{-s t} f^{\prime}(t) d t
$$

and integration by parts gives

$$
\begin{aligned}
& {\left[\begin{array}{ll}
u=e^{-s t}, & d v=f^{\prime}(t) d t \\
d u=-s e^{-s t} d t, & v=f(t)
\end{array}\right]} \\
& L\left\{f^{\prime}(t)\right\}=\left.e^{-s t} f(t)\right|_{0} ^{+\infty}+s \int_{0}^{+\infty} e^{-s t} f(t) d t=-f(0)+s F(s)
\end{aligned}
$$

but $|f(t)|<M e^{S_{0} t}$ and $\operatorname{Re} s=p>S_{0}$. On the other hand

$$
\begin{aligned}
F(s)=\int_{0}^{+\infty} f(t) e^{-s t} d t, \text { hence } & \\
L\left\{f^{\prime}(t)\right\} & =-f(0)+s F(s)
\end{aligned}
$$

We are not going to consider the other properties, as far as these properties are sufficient for our study.

\section{Laplace Transform for Population Growth}

How can people alter their size? The population is influenced by four variables. In a population, the birth rate is increasing and the population death rate is decreasing. New entries also exist in population (migration) or population (immigration). There are also fresh entries. The above mentioned statements have a easy equation [1]

$$
\Delta P=B-D+I-E
$$

Where: $\Delta P=$ the change in the size of population in time $t$

$$
\begin{aligned}
& B=\text { birth rate } \\
& D=\text { death rate } \\
& I=\text { migration rate } \\
& E=\text { immigration rate }
\end{aligned}
$$

If the population is supposed to be 'closed', then we do not have a mobility of the population, so that

$$
\Delta P=B-D
$$

The simplest model is if density-independent population growth is regarded. Independence in density implies that the population size does not affect the birth and death rate. Therefore, birth and death is directly proportional to people. [1] 


$$
P^{\prime}(t)=r P(t)
$$

(The English mathematician Thomas R. Malthus brought this model to population growth in 1798). The speed of change per capita $r=P^{\prime} / P$ in this model is continuous, positive when it increases and negative when it $P$ decreases [1]

Applying the Laplace transform on both sides of (4), we have [3]

$$
L\left\{P^{\prime}(t)\right\}=L\{r P(t)\}
$$

Now applying the original derivation property, on (5), we have

$$
s P(s)-P(0)=r P(s)
$$

where $P(0)$ is the population at time $t=0$

$$
\begin{aligned}
(s-r) P(s)=P(0) \\
P(s)=\frac{P(0)}{s-r}
\end{aligned}
$$

Operating inverse Laplace transform on both sides of (6), we have

so

$$
L^{-1}\{P(s)\}=L^{-1}\left\{\frac{P(0)}{s-r}\right\}=P(0) e^{r t}
$$

$$
P(t)=P(0) e^{r t}
$$

Now using the equation (7) we can find $r$ and calculate the population for different years. We will apply the equation (7) for the Albanian population.

Using the data with $t=0$ corresponding to the year 1990, we have $P(0)=3,188,380$. We can solve $r$ using the fact that $P=3,080,124$ when $t=10$ which is the year 2000. [1], [4] By using (7)

$$
3,080,124=3,188,380 e^{10 r} \Rightarrow r=-0.00345
$$

The general solution is given to us

$$
P(t)=3,188,380 e^{-0.00345 t}
$$

We are now going to compute the population at later years and compare it to the actual data. The following chart represents it. [1], [7], [8]

\begin{tabular}{ccc}
\hline \hline Year & Actual & Predicted \\
\hline 200 & & $3,069,64$ \\
1 & 3063320 & 8 \\
200 & & $3,059,07$ \\
2 & 3057018 & 6 \\
200 & $3,044,99$ & $3,048,54$ \\
3 & 3 & 0 \\
200 & $3,034,23$ & $3,038,04$ \\
4 & 1 & 1 \\
200 & $3,019,63$ & $3,027,57$
\end{tabular}

\begin{tabular}{ccc}
5 & 4 & 7 \\
200 & $3,003,32$ & $3,017,15$ \\
6 & 9 & 0 \\
200 & $2,981,75$ & $3,006,75$ \\
7 & 5 & 9 \\
200 & $2,958,26$ & $2,996,40$ \\
8 & 6 & 4 \\
200 & $2,936,35$ & $2,986,08$ \\
9 & 5 & 4 \\
201 & $2,918,67$ & $2,975,80$ \\
0 & 4 & 0 \\
201 & $2,907,36$ & $2,965,55$ \\
1 & 8 & 1 \\
201 & $2,903,00$ & $2,955,33$ \\
2 & 8 & 7 \\
201 & $2,897,77$ & $2,945,15$ \\
3 & 0 & 9 \\
201 & $2,892,39$ & $2,935,01$ \\
4 & 4 & 6 \\
201 & $2,885,79$ & $2,924,90$ \\
5 & 6 & 7 \\
201 & $2,875,59$ & $2,914,83$ \\
6 & 2 & 4 \\
201 & $2,876,59$ & $2,904,79$ \\
7 & 1 & 5 \\
201 & $2,870,32$ & $2,894,79$ \\
8 & 4 & 1 \\
201 & $2,862,42$ & $2,884,82$ \\
9 & 7 & 1 \\
\hline \hline & & \\
\hline
\end{tabular}

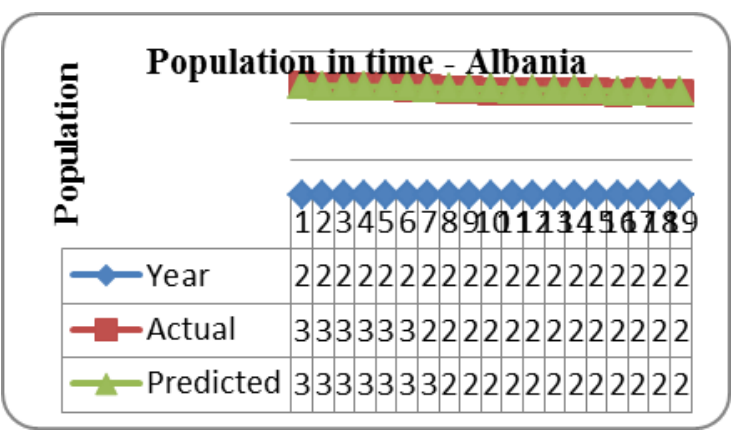

As shown in Figure 2, this model can now be used for making future population predictions. Between 2001 and 2019, we have a good agreement between actual and predicted data. It provides us some hope to predict the future. So we can plug in our model to estimate the population in millions that year., [1]

$$
P(2025)=3,188,380 \mathrm{e}^{-0.00345 \times 35}=2,825,719
$$

\section{Conclusions}

Laplace transformation is the easiest and most expensive way to solve many of the different technical issues which occur when solving them directly. The transformation of Laplace allows us to readily achieve a definitive analytical 


\section{LAPLACE TRANSFORM, APPLICATION IN POPULATION GROWT}

solution to solve population growth. The Malthus model allows us to predict the population size. Clearly, the forecast information is almost the same as the actual information. An instance of how accurate this model is is is the forecast about the Albanian people. The predicted and current information on the Albanian population for 2001-2019 are very much in common with each other. This gives us an incredible tool to predict future population growth.

\section{References}

[1]A. Daci, "Mathematical Models For Population Projection in Albania," Journal of Multidisciplinary Engineering Science and Technology (JMEST) ISSN: 2458-9403, Vol. 3, pp. 5486-5489, Issue 8, August 2016.

[2]A. Daci and S. Tola, "Application Of Laplace Transform In Finance," International Scientific Journal, Scientific Technical Union Of Mechanical Engineering, "Industry 4.0” Issn (Print) 2535-0986, Issn (Web) 2603-2929, Year II, Issue 4, pp. 130-133 / 2018.

[3]S. Aggarwal, A. R. Gupta, D. P. Singh, N. Asthana and N. Kumar, "Application of Laplace Transform for Solving Population Growth and Decay Problems", International Journal of Latest Technology in Engineering, Management \& Applied Science (IJLTEMAS), ISSN 2278-2540, Volume VII, Issue IX, pp. 141-144, September 2018.

[4]D. Hathout, "Modeling population Growth: Exponantial Hyperbolic Modeling," Applied Mathematics, Issue 4, pp. 299-304, January 2013.

[5]L. Mejlbro \& Ventus Publishing Aps, The Laplace Transformation IGeneral Theoty - Complex Functions Theory a-4,@2010, ISBN 978-87-7681-718-3, pp. 15-27.

[6]J. Malita, Analiza Komplekse, Teori dhe Ushtrime, Kapitulli 8, fq. 199-237, Tiranë, 2009.

[7] http://databaza.instat.gov.al/pxweb/sq/DST/START__DE/

[8] http://databaza.instat.gov.al/pxweb/sq/DST/START_DE/NewPOP_000 2/chart/chartViewPoint/?rxid=6bdbadad-51ac-4f9d-b261-f5bb20670 $\underline{\mathrm{a} 46}$

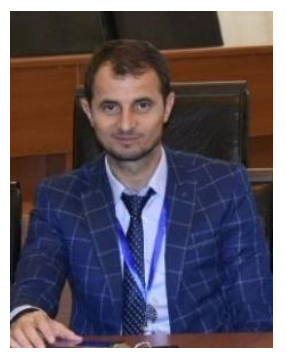

Alfred Daci was born in Kruja, Albania in 1981. He graduated in Special Mathematics at the Faculty of Natural Sciences, University of Tirana, in 2005. In 2008 he concluded his Post University Studies at the Faculty of Natural Sciences, UT, at the section of Differential Equations and Mathematics Analysis.

From 2011 until 2016, were the years he spent in his doctorial studies, becoming a PhD in Mathematics at the Polytechnic University of Tirana, Faculty of Mathematical Engineering and Physical Engineering. From 2005 to 2009 Alfred has been part of the academic staff at the Faculty of Electronic Engineering, "Skenderbej" Military University. He was elected Head of Mathematics Section. He has been the curriculum compiler, as well as a lecturer. Since 2009 up to the present he has been a member of the staff of Department of Mathematics, Faculty of Mathematical Engineering and Physical Engineering, Polytechnic University of Tirana. From 2007 up to the present he has been chosen to be a part time lecturer in various Universities, teaching different subjects. Alfred is a member of several Editorial Boards, such as

a) Editorial Board of Research Journal of Mathematics and Computer Science

b) Editorial Board of Scientific Research and Reviews

c) Editorial Board of Global Journal of Library and Information Science

d) Editorial Board of American Journal of Basic and Applied Sciences

He has published a considerable number of papers in national and international journals. Furthermore, he has taken part in various conferences - national and international.

Alfred's rich experience in teaching and research in different universities, conferences and trainings has broaden his interest in different research area including. However, his research is focused on Dynamical Systems. 